\title{
NEETs in Limburg: trends, spreiding, en duiding
}

Citation for published version (APA):

Levels, M., de Grip, A., \& Dicks, A. (2018). NEETs in Limburg: trends, spreiding, en duiding. ROA. ROA Fact Sheets No. 002 https://doi.org/10.26481/umarof.2018002

Document status and date:

Published: 01/01/2018

DOI:

10.26481/umarof.2018002

Document Version:

Publisher's PDF, also known as Version of record

\section{Please check the document version of this publication:}

- A submitted manuscript is the version of the article upon submission and before peer-review. There can be important differences between the submitted version and the official published version of record.

People interested in the research are advised to contact the author for the final version of the publication, or visit the DOI to the publisher's website.

- The final author version and the galley proof are versions of the publication after peer review.

- The final published version features the final layout of the paper including the volume, issue and page numbers.

Link to publication

\footnotetext{
General rights rights.

- You may freely distribute the URL identifying the publication in the public portal. please follow below link for the End User Agreement:

www.umlib.nl/taverne-license

Take down policy

If you believe that this document breaches copyright please contact us at:

repository@maastrichtuniversity.nl

providing details and we will investigate your claim.
}

Copyright and moral rights for the publications made accessible in the public portal are retained by the authors and/or other copyright owners and it is a condition of accessing publications that users recognise and abide by the legal requirements associated with these

- Users may download and print one copy of any publication from the public portal for the purpose of private study or research.

- You may not further distribute the material or use it for any profit-making activity or commercial gain

If the publication is distributed under the terms of Article $25 \mathrm{fa}$ of the Dutch Copyright Act, indicated by the "Taverne" license above, 


\section{Maastricht University $\&$ ROA}

\section{NEETs in Limburg: trends, spreiding, en duiding}

\section{ROA Fact Sheet}

ROA-F-2018/2

Researchcentrum voor Onderwijs en Arbeidsmarkt | ROA Research Centre For Education and the Labour Market / ROA 


\section{Snelle feiten en cijfers}

I. Limburg kent ongeveer 20.900 NEETs. Dat is verhoudingsgewijs meer dan het landelijk gemiddelde.

2. In Limburg neemt het aantal NEETs nog steeds toe. Dat gaat tegen de landelijke trend in.

3. Een derde van de Limburgse NEETs is migrant. Die zijn meestal maar kort NEET.

4. Niet iedereen is kwetsbaar. Het meest kwetsbaar zijn de 8.820 langdurige NEETs.

5. Vooral in de omgeving Parkstad is het aantal problematische NEETs relatief hoog.

\section{Inleiding}

Om de arbeidsmarktkansen van jongeren gedurende de school-naar-werktransitie te meten, maakten onderzoekers en beleidsmakers jarenlang voornamelijk gebruik van het jeugdwerkloosheidspercentage. Dat had een nadeel. Wie werkloos is, is op zoek naar werk. Wie niet op zoek is naar werk, valt buiten de definitie. Hierdoor bleven kwetsbare jongeren die al vroeg buiten de arbeidsmarkt staan vaak buiten beeld. Om deze kwetsbare jongeren beter in kaart te brengen, kijken we naar de zogeheten NEETs: jongeren die Not in Employment, Education, or Training verkeren. Een status als NEET blijkt een sterke voorspeller te zijn van latere sociaaleconomische marginalisering, crimineel gedrag, ongezondheid, ongewenste zwangerschappen, en langdurige economische inactiviteit. NEET lijkt dan ook een goede indicator om de kwetsbaarheid van jongeren in beeld te brengen.

Voor veel overheden is het terugbrengen van het aantal NEETs daarom een belangrijke beleidslijn. Ook in Nederland. Nederland heeft internationaal gezien relatief weinig NEETs: in 2015 was zo'n $10.3 \%$ van alle jongeren tussen de 15 en 27 jaar oud te classificeren als NEET. ${ }^{1}$ Limburg loopt nationaal gezien echter wat achter. In 2015 was $13 \%$ van de Limburgse jongeren tussen de 15 en 27 jaar langer dan een halfjaar NEET. Dat is hoger dan het landelijk gemiddelde.

In Figuur I geven we de ontwikkeling van het percentage NEETs tussen 2005 en 2015 weer voor alle Nederlandse provincies. In alle provincies is een dalende trend in het aantal NEETs te zien tot aan 2008. In dat jaar begint de economische crisis haar sporen op de arbeidsmarkt na te laten. In alle provincies neemt het aantal NEET jongeren gedurende vijf jaar gestaag toe. In 2013 breekt de landelijke

I Deze cijfers zijn gebaseerd op register data, niet op data uit Enquête Beroepsbevolking (EBB). trend: de arbeidsmarkt trekt landelijk aan, en tussen 2013 en 2015 zien we in de meeste provincies het aantal NEETs weer afnemen. Er zijn twee belangrijke uitzonderingen op deze trend: de provincies Limburg en Groningen. In deze provincies neemt het percentage NEETs tegen de nationale trend in verder toe, in plaats van af. Dat kan betekenen dat NEETs in Limburg en Groningen minder goed in staat zijn de door de aantrekkende economie verbeterde arbeidsmarktkansen te verzilveren dan NEETs in andere Nederlandse provincies.

\section{Waal of NEET kwetsbaar?}

Een van de redenen zou kunnen zijn, dat NEETs in Limburg kwetsbaarder zijn dan elders. NEETs worden vaak gezien als een homogeen kwetsbare groep. Maar dat is niet het geval. Dat heeft te maken met de wijze waarop het begrip is gedefinieerd: je bent NEET als je a) jong bent, b) niet werkt, en c) geen onderwijs of training volgt. Veel kwetsbare jongeren vallen inderdaad onder deze noemer. Langdurig zieken en gehandicapten bijvoorbeeld, of mensen met een onderwijsachtergrond waarnaar geen arbeidsmarktvraag bestaat. Maar in de groep NEETs vinden we ook backpackers die bewust een gap year nemen, jongeren die kort werkloos zijn als ze de transitie van school naar werk maken, startende ondernemers, of jonge ouders die er bewust voor kiezen de arbeidsmarkt (tijdelijk) te verlaten.

Niet alle NEETs zijn dus problematisch, en sommigen zijn waarschijnlijk heel goed in staat de transitie van school naar werk te maken. Om de ernst van de NEET problematiek beter in kaart te kunnen brengen, volgen we de loopbanen van jongeren tussen 2011 en 2015 op basis van de registerdata van het CBS. We bezien per maand wat de hoofdactiviteit van deze jongeren was, waarbij we kunnen zien of jongeren inkomsten uit werk ontvangen (53.700) of bekostigd onderwijs volgen (I00.530). We zien ook of ze studiefinanciering ontvangen voor een studie in het buitenland, of inkomen genieten uit buitenlands werk. Ongeveer 20.900 jongeren in Limburg zijn NEET. Daar zitten dus werklozen bij, maar ook mensen die helemaal buiten de arbeidsmarkt staan.

Figuur 2 laat zien dat Limburgse NEETs zijn in te delen in zes groepen ${ }^{2}$ :

- Langdurig NEET: deze groep is gedurende het grootste deel van de school-naar-werktransitie NEET. Het betreft hier iets minder dan de helft (42\%) van alle Limburgse jongeren die in 2015 NEET waren.

- Kort, maar vaak NEET: Deze groep kent een vrij onstuimige transitie van school naar werk, die wordt

2 Deze groepen zijn geconstrueerd op basis van een sequentie-analyse. 
Figuur 1

NEET aandeel onder 15-27 jarigen in Nederlandse provincies tussen 2005 en 2015
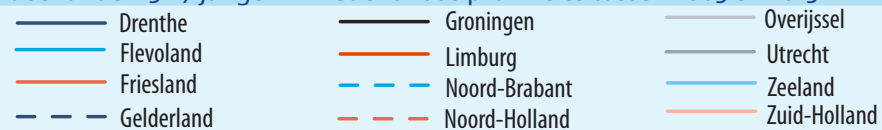

$15 \%$

- - Noord-Holland

Zuid-Holland
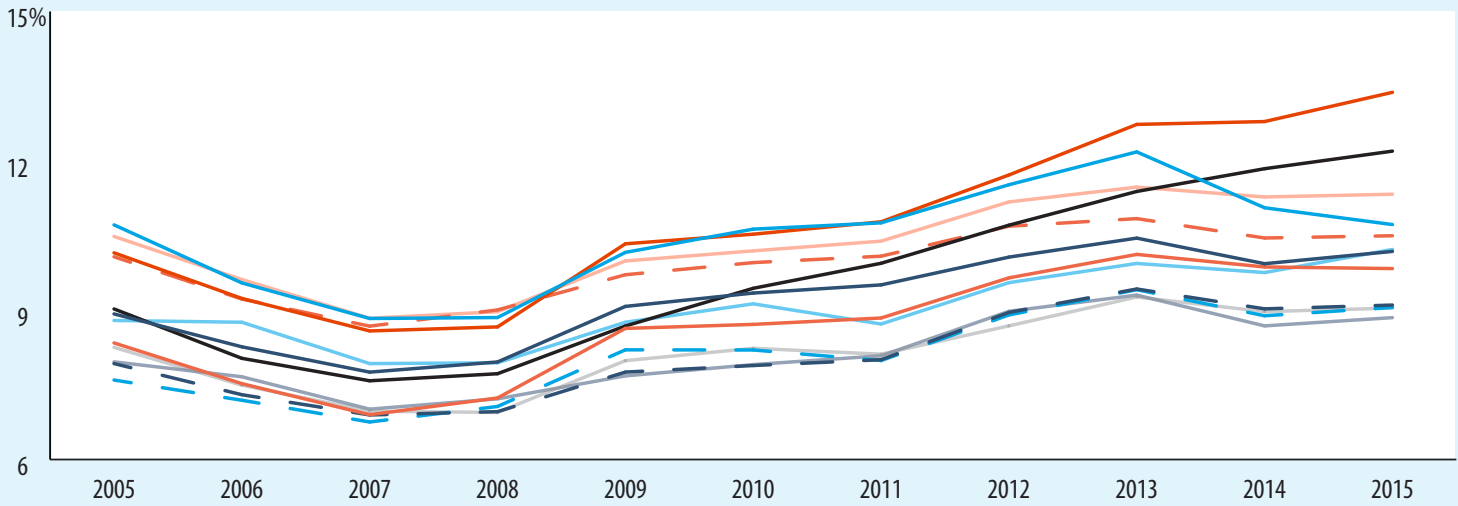

Noot: cijfers zijn tellingen op 1 oktober

Bron: CBS Statline

Figuur 2

Hoofdactiviteit van Limburgse jongeren in 2015, en de school-naar-werk transitie van Limburgse jongeren (15-27) die in 2015 NEET waren

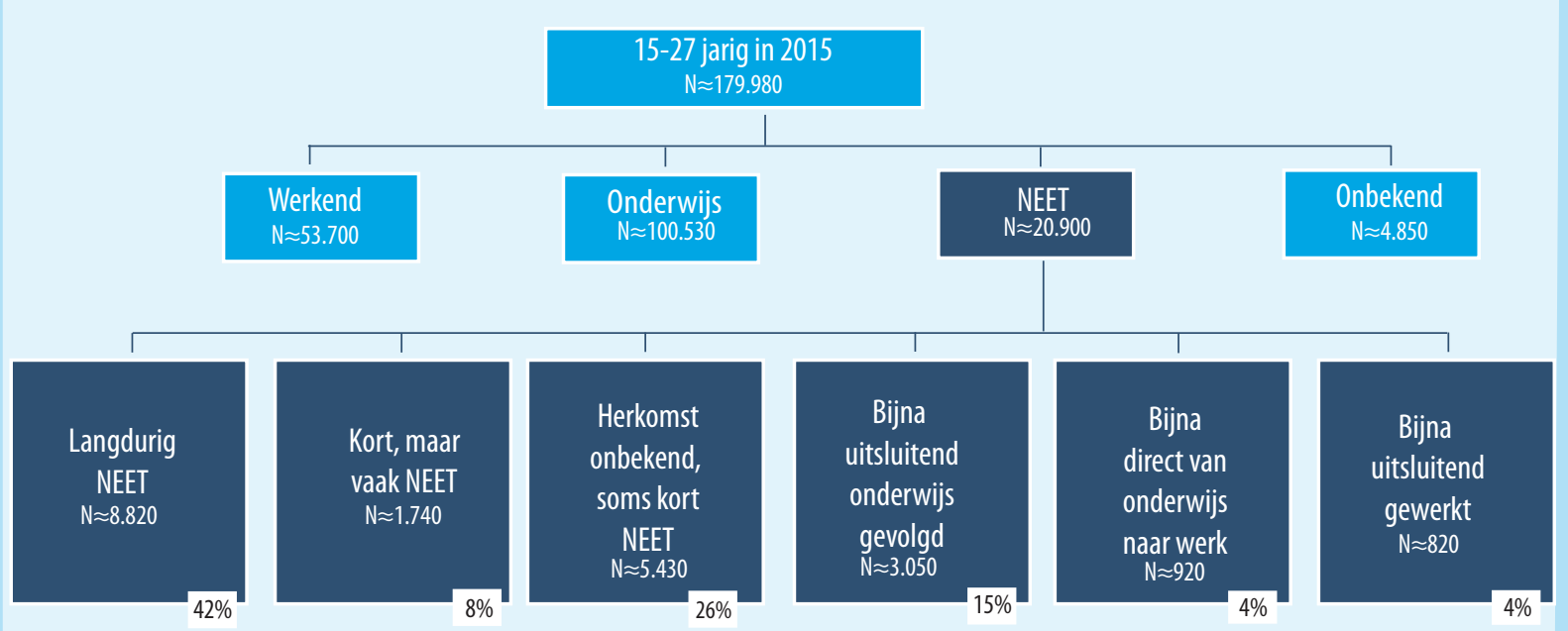

Noot: iets minder dan 1\% van de NEET is niet in deze categorieën in te delen (ongeveer 120 mensen).

Bron: Social Statistische Bestanden, eigen berekening 
Figuur 3

gekenmerkt door een regelmatige status als NEET (8\%).

- Herkomst onbekend, soms kort NEET: NEETs die niet eerder in de registers voorkwamen (26\%). Hoewel hun herkomst onbekend is, weten we op basis van de registers wel dat het hier bijna uitsluitend om immigranten gaat. Ongeveer $64 \%$ van hen zijn Westerse migranten. De rest is niet-westers. Dat zouden bv. asielzoekers kunnen zijn.

- Bijna uitsluitend onderwijs gevolgd: Jongeren die in 20I5 NEET waren, maar die voornamelijk onderwijs volgden tussen $201 \mathrm{I}$ en 2015 ( $15 \%$ ).

- Bijna direct van onderwijs naar werk: Jongeren die de school-naar-werk transitie vrij vloeiend maakten, maar desondanks in 2015 NEET waren $(4 \%)$.

- Bijna uitsluitend gewerkt: jongeren die tussen $201 \mathrm{I}$ en 2015 voornamelijk werkten (4\%), maar in 2015 toch NEET waren.

Hieruit kunnen drie conclusies getrokken worden:

I. Bijna de helft van de Limburgse NEETs staat langdurig buiten de arbeidsmarkt (42\%). Het gaat dan in totaal om ongeveer 8.820 jongeren.

2. Slechts een fractie van de Limburgse NEETs (8\%) heeft een onstuimige school-naar-werk transitie doorgemaakt.

3. Iets meer dan een kwart van alle Limburgse NEETs heeft een migratieachtergrond. Van hen is $64 \%$ Westers, en $33 \%$ niet-Westers. Dit zouden bijvoorbeeld seizoenarbeiders kunnen zijn, vluchtelingen, of mensen die met een studerende partner meekomen. Verdere informatie benodigd om de groep nader te duiden ontbreekt vooralsnog, maar veel van hen zijn maar kortstondig NEET.

\section{Waar wonen de meest problematische Limburgse}

\section{NEETs?}

Waar wonen de langdurige NEETs? Dat laten we zien in Figuur 3. Binnen Limburg zijn de meest problematische NEETs vooral te vinden in gemeenten in de Oostelijke Mijnstreek: Kerkrade (IO\%) en Heerlen (9\%) zijn provinciale uitschieters, maar ook in Brunssum bevinden zich relatief veel langdurige NEETs. In steden als Maastricht, Venlo en Weert lijkt het aantal relatief mee te vallen.

Jongeren die in 2015 NEET waren, en dat gedurende hun hele schoolnaar-werk transitie langdurig geweest zijn

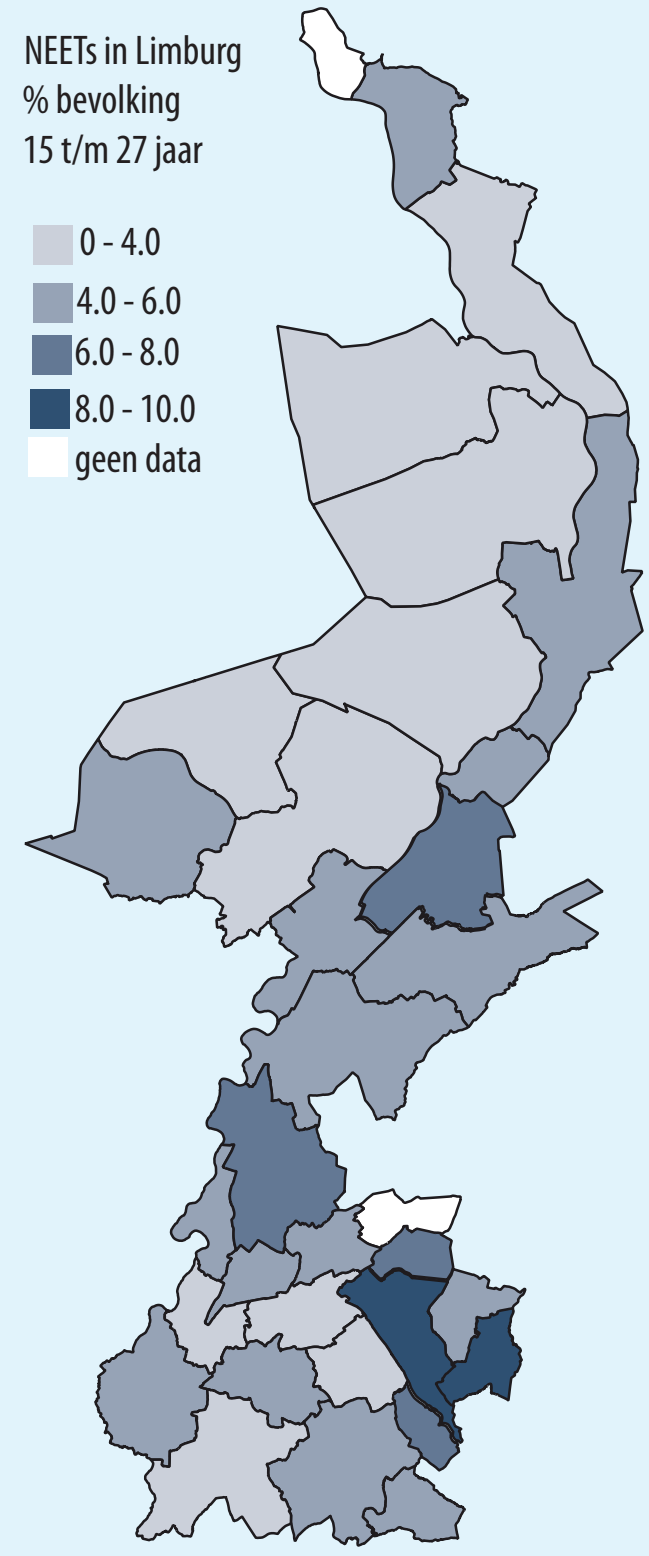

Bron: Sociaal Statististische Bestanden, eigen berekening 


\section{LIMBURG}

Deze factsheet is een onderdeel van het meerjarenprogramma 4Limburg dat een bijdrage wil leveren om de Limburgse samenleving meer duurzaam, vitaal en inclusief te maken. Het doel van dit programma is om, in nauwe samenwerking met de Universiteit Maastricht, Provincie Limburg en ketenpartners zoals gemeenten, UWV en bedrijfsleven, via een trendbreuk de arbeidsparticipatie én de vitaliteit in Limburg naar een hoger niveau te tillen. Voor de Limburgse welvaartsontwikkeling is het van groot belang dat jongeren met de juiste bagage aan de start verschijnen en niet al te vroeg afhankelijk worden van een uitkering. Als opstap voor het te voeren beleid geeft deze factsheet inzicht in de ontwikkeling van de groep jongeren die geen onderwijs volgen of werk hebben (ook wel aangeduid als de NEETs: "Not in Employment, Education or Training") en inzicht in de omvang van de problematiek in de verschillende gemeentes in Limburg.

\section{Colofon}

() Researchcentrum voor Onderwijs en Arbeidsmarkt Niets uit deze uitgave mag op enige manier worden verveelvoudigd zonder voorafgaande schriftelijke toestemming van de directeur van het ROA.

Researchcentrum voor Onderwijs en Arbeidsmarkt

Maastricht University

School of Business and Economics

secretary-roa-sbe@maastrichtuniversity.nl

www.roa.nl

Vormgeving

ROA secretariaat, Maastricht

maart 2018 